\title{
Effects of carnitine on oxidative stress response to intravenous iron administration to patients with CKD: impact of haptoglobin phenotype
}

Zaher Armaly ${ }^{1,3^{*}}$, Amir Abd El Qader ${ }^{1,3}$, Adel Jabbour ${ }^{2,3}$, Kamal Hassan $^{4}$, Rawi Ramadan ${ }^{5}$, Abdalla Bowirrat ${ }^{1,3}$ and Bishara Bisharat ${ }^{1,3}$

\begin{abstract}
Background: Anemia is a common disorder in CKD patients. It is largely attributed to decreased erythropoietin (EPO) production and iron deficiency. Therefore, besides EPO, therapy includes iron replenishment. However, the latter induces oxidative stress. Haptoglobin $(\mathrm{Hp})$ protein is the main line of defense against the oxidative effects of Hemoglobin/Iron. There are 3 genotypes: $1-1,2-1$ and $2-2$. Hp 2-2 protein is inferior to $\mathrm{Hp} 1-1$ as antioxidant. So far, there is no evidence whether haptoglobin phenotype affects iron-induced oxidative stress in CKD patients. Therefore, the present study examines the influence of carnitine treatment on the intravenous iron administration (IVIR)-induced oxidative stress in CKD patients, and whether Hp phenotype affects this response.

Methods: Trial registration: Current Controlled Trials ISRCTN5700858. This study included 26 anemic $(\mathrm{Hb}=10.23 \pm$ 0.28) CKD patients (stages $3-4$ ) that were given a weekly IVIR (Sodium ferric gluconate, [125 mg/100 ml] for 8 weeks, and during weeks 5-8 also received Carnitine (20 mg/kg, IV) prior to IVIR. Weekly blood samples were drawn before and after each IVIR for Hp phenotype, C-reactive protein (CRP), advanced oxidative protein products (AOPP), neutrophil gelatinase-associated lipocalin (NGAL), besides complete blood count and biochemical analyses.

Results: Eight percent of CKD patients were Hp1-1, 19 \% Hp2-1, and 73 \% Hp2-2. IVIR for 4 weeks did not increase hemoglobin levels, yet worsened the oxidative burden as was evident by elevated plasma levels of AOPP. The highest increase in AOPP was observed in Hp2-2 patients. Simultaneous administration of Carnitine with IVIR abolished the IVIR-induced oxidative stress as evident by preventing the elevations in AOPP and NGAL, preferentially in patients with Hp2-2 phenotype.

Conclusions: This study demonstrates that Hp2-2 is a significant risk factor for IVIR-induced oxidative stress in CKD patients. Our finding, that co-administration of Carnitine with IVIR preferentially attenuates the adverse consequences of IVIR, suggests a role for Carnitine therapy in these patients.
\end{abstract}

Keywords: Anemia, Chronic kidney disease, Intravenous iron administration, Oxidative stress, Carnitine, Haptoglobin

\section{Background}

Chronic kidney disease (CKD) is a global public health problem, affecting tens of millions around the world $[1,2]$. The alarming increase in the prevalence of CKD is largely attributed to the dramatic global increase of diabetes and hypertension incidence [2]. One of the major complications of CKD, especially the advanced stages of

\footnotetext{
* Correspondence: ZaherArmaly@NAZHOSP.com

'Department of Nephrology, Nazareth Hospital-EMMS, Nazareth 16100, Israel

${ }^{3}$ Galilee Faculty of Medicine - Bar Ilan University, Zafed, Israel

Full list of author information is available at the end of the article
}

the disease, is anemia [3]. The latter is associated with poor clinical outcomes as evident by enhanced incidence of cardiovascular events and the risk of death in patients with CKD [4-6]. Thus, correction of anemia is considered as a major component in the integral therapy of CKD adverse consequences [7, 8]. The mechanisms underlying anemia in CKD patients is attributed to several factors including decreased erythropoietin (EPO) production, low iron stores, and chronic inflammation [7]. Therefore, therapy includes not only recombinant EPO, but also iron replenishment [8-10]. Intravenous 
iron administration (IVIR) in these CKD patients is the most efficacious and favored route of supplementation to enhance red blood cell production by recombinant human erythropoietin administration $[7,8]$. There are several iron preparations for IV administration: iron sucrose, sodium ferric gluconate, low- and high molecular weight iron dextran, ferric carboxymaltose, and ferumoxytol $[9,10]$. However, despite their efficacy as expressed by improved erythropoietic response in CKD subjects, exposure to IV iron is associated with enhancement of free radical generation and oxidative stress, thus aggravating the already existed oxidative burden in these patients [11-14]. There are several markers of free radical activities such as carbonyl reactive derivatives (CRD), thiol groups (SH), malondialdehyde (MDA), and antioxidant enzyme activities (superoxide dismutase, SOD and glutathione peroxidase, GPX) $[15,16]$. Additional biomarker that represents plasma protein oxidation is advanced protein oxidation products (AOPP), where it has recently been applied to assess the oxidative stress and inflammation in several pathological conditions [17-20]. Enhanced oxidative stress and inflammation are known to induce direct cellular damage and possibly increasing the risk of atherosclerotic disease in CKD and hemodialysis patients [21-23]. Several studies have shown that the severity of oxidative stress-induced cardiovascular complications in various disease states is affected by haptoglobin $(\mathrm{Hp})$ genotype $[24,25]$. There are two classes of functional alleles $\mathrm{Hp} \mathrm{1-1,1-2}$ and $2-2$. Hp binds to free hemoglobin $(\mathrm{Hb})$ released from blood cells as part of red cell turnover, thus inhibiting the oxidative tissue damage resulting from free $\mathrm{Hb}$ through heme iron [26, 27]. Hp alleles differ in their ability to clear free $\mathrm{Hb}$ from the plasma where $\mathrm{Hp}$ [1]-Hb complexes are cleared more efficiently from the plasma than $\mathrm{Hp}$ [2]-Hb complexes [27], thus subjects with Hp 2-2 are more prone to oxidative stress [28].

Current criteria for diagnosis and classification of AKI are highly dependent on changes in $\mathrm{SCr}[29,30]$. However, in the setting of acute kidney injury (AKI), the time relationship between changes in $\mathrm{SCr}$ and concomitant changes in GFR do not allow accurately estimating timing of injury and severity of dysfunction [31]. Recent studies have attempted to identify by a genome-wide interrogation strategy genes that are induced very early after acute ischemia of kidney in animal models, whose protein products might serve as novel biomarkers for the initiation phase of AKI. Actually, many potential markers have been studied, including neutrophil gelatinase-associated lipocalin (NGAL), kidney injury molecule- 1 (KIM-1), and others [32, 33]. Among them, NGAL is one of the most strikingly up-regulated genes and overexpressed proteins following AKI [32]. NGAL increased in urine early after renal ischemia in mouse and rat models $[34,35]$, yet has not been documented in human. The additional and earlier finding that the serum and urine NGAL levels were strikingly elevated in children with AKI after cardiopulmonary bypass [35] suggests that NGAL might be a specific, and highly predictive early biomarker for AKI also in humans. Kidney injury molecule-1 (KIM-1) is a marker for proximal tubular injury, the hallmark of virtually all proteinuric, toxic and ischemic renal diseases [33, 36, 37].

Several interventions have been attempted to counteract the deleterious effects of IV induced oxidative stress in dialysis patients including administration of substances with antioxidant properties, such as $\alpha$-tocopherol, angiotensin converting enzyme inhibitors, vitamin $\mathrm{E}$, $\mathrm{N}$-acetyl cysteine (NAC) prior to IV iron administration $[15,38]$. Unfortunately, none of these therapeutic maneuvers exerted beneficial effects against oxygen free radical injury. However, there is no doubt that any potential therapies should encounter the altered mitochondrial function. One of these approaches is the use of carnitine since it may preserve mitochondrial function and subsequently reduced oxidative burden. In line with this concept, several randomized, controlled studies and a meta-analysis have shown that L-carnitine supplementation might have a positive effect on response to EPO in long term HD patients [19, 39-42]. Unfortunately, there is no evidence whether this approach is also beneficial in earlier-stage CKD patients. Thus the present study was designed to investigate the effect of L-Carnitine therapy on oxidative stress and the inflammatory response to intravenous iron administration (IVIR) in CKD patients. In addition, we examined whether the extent of oxidative stress in these patients is affected by the Hp phenotype.

\section{Methods}

This was a prospective, non-randomized, open-label, crossover study of the effects of IV Carnitine supplementation on oxidative stress in CKD patients receiving IV iron therapy. The study was approved by the Nazareth Hospital EMMS Human Research Review Committee and carried at Nazareth Hospital. All patients provided informed consent. Trial registration: Current Controlled Trials ISRCTN5700858. (https://clinicaltrials.gov/ct2/show/ NCT02312414), Date of registration is December 5th, 2014.

\section{Inclusion criteria}

1. Patients that have been diagnosed as suffering from chronic kidney diseases at stages 3-4 and confirmed by MDRD.

2. CKD patients with $\mathrm{Hb}$ of $\leq 10.2 \mathrm{~g} \%$.

3. At age $\geq 18 \mathrm{y}$. 


\section{Exclusion criteria}

1. Pregnant women.

2. Patient with CKD stage 5 on Dialysis.

3. Patients with severe liver diseases.

4. Patients with severe CHF.

5. Inter-current illness such as fever.

6. Allergic rhinitis.

\section{Study design}

Among 28 eligible patients 2 patients were dropped from the study due to infection and hospitalization (Fig. 1).

Sample size was determined based on the standard deviation of the obtained preliminary data. For this purpose we applied the following

$$
\begin{aligned}
& n_{1}=\frac{\left(Z_{1-\alpha / 2}+Z_{1-\beta}\right)^{2} \sigma^{2}(k+1)}{k \Delta^{2}} \\
& n_{2}=k n_{1}
\end{aligned}
$$

Significance $\alpha 5 \%$

Confidence 1 - $\alpha 95 \%$

SD $\sigma 3.0$

Strength $\beta 99 \%$

Effect size delta 0.29

$\mathrm{K}=1$

Sample size 25

The demographic and laboratory data of the studied patients are listed in Table 1 . This study included 26 anemic $(\mathrm{Hb}=10.23 \pm 0.25)$ CKD patients (stages 3-4) that were given by Dr. ZA at Nazareth Hospital a weekly IVIR (Sodium ferric gluconate, [125 mg/100 ml] for
Table 1 Baseline Demographic and Laboratory Data of the 26 Studied Patients

\begin{tabular}{ll}
\hline Parameter & Value \\
\hline Age, mean \pm SD (yrs) & $63.84 \pm 2.84$ \\
Gender (Male : Female) & $13: 13$ \\
Etiology of CKD & \\
$\quad$ Disease (no.) & 18 \\
$\quad$ Diabetes mellitus & 16 \\
$\quad$ Hypertension & 3 \\
$\quad$ Other & $33.2 \pm 4.02$ \\
MDRD-GFR, (ml/min/1.73 $\mathrm{m}^{2}$ ) & \\
Stage of CKD (no.) & 11 \\
Stage 3 & 15 \\
Stage 4 & $10.3 \pm 0.25$ \\
Hemoglobin (g \%)
\end{tabular}

8 weeks, and during weeks $5-8$ also received Carnitine (20 $\mathrm{mg} / \mathrm{kg}$, IV) prior to IVIR administration). To minimize potential bias each patient served as its own control. Weekly blood samples were drawn before and after each IVIR for C-Reactive protein (CRP), advanced oxidative protein products (AOPP), neutrophil gelatinaseassociated lipocalin (NGAL), in addition to routine complete blood count and biochemical analyses.

\section{Chemical and hematological analysis} AOPP (Advanced oxidation protein products)

A novel spectrophotometric assay which allows detecting advanced oxidation protein products (AOPP) in uremic plasma was used. AOPP levels were measured with the

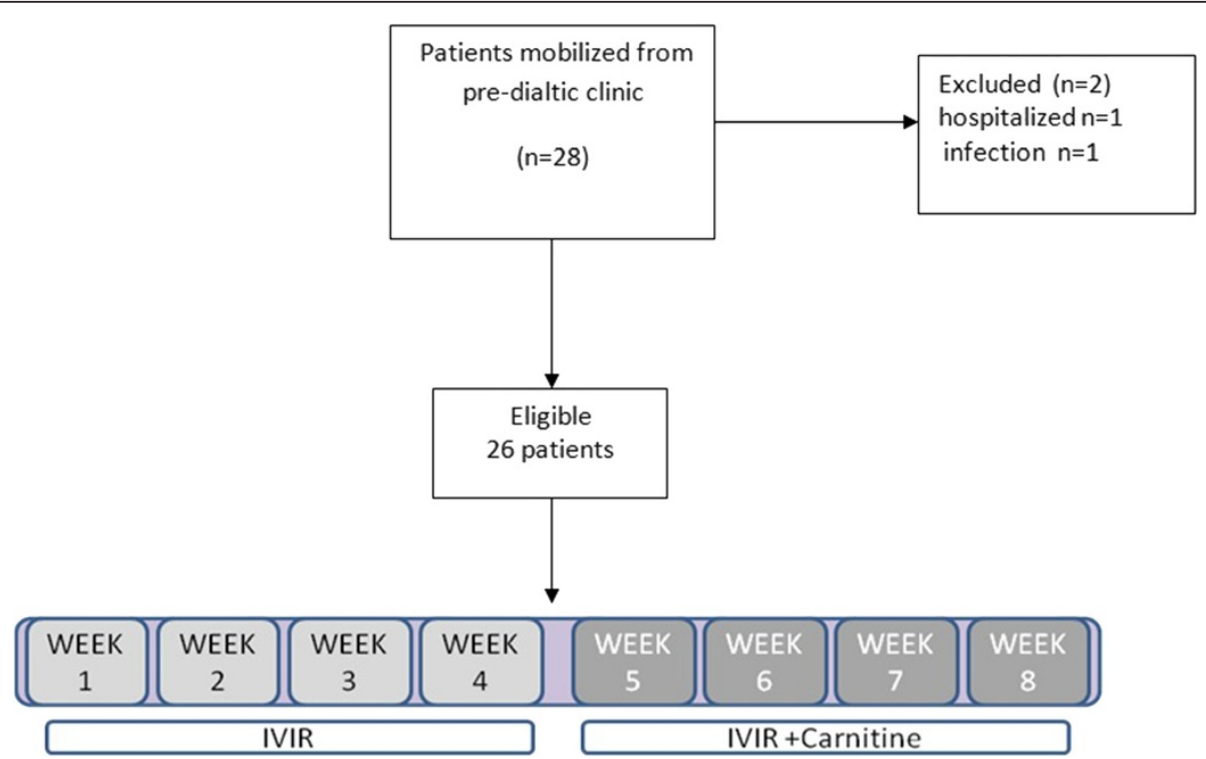

Fig. 1 Selection of anemic CKD patients for examination of the effects of carnitine on oxidative stress response to intravenous iron administration and the impact of haptoglobin phenotype 
Witko-Sarsat method [19] of optical density analysis in patient blood samples. AOPP maximum absorption is at a wavelength of $340 \mathrm{~nm}$ under acidic conditions, therefor this wavelength provides the best indication of the level of the AOPP in the samples. By size-exclusion chromatography, AOPP are retrieved in two distinct peaks at 600 and below $80 \mathrm{kDa}$ in uremic plasma, while no such peaks are found in control plasma.

\section{Determination of NGAL}

This biomarker was determined in specimens of plasma that were stored at $-80{ }^{\circ} \mathrm{C}$ until analysis. Blood specimens were collected aseptically into EDTA-containing tubes, centrifuged at $3000 \mathrm{rpm}$ and serum separated and stored at $-80{ }^{\circ} \mathrm{C}$ until testing. Plasma level of NGAL was measured with a commercially available ELISA kit purchased from Bio Porto Diagnostics (Gentofte, Denmark).

\section{Haptoglobin phenotype}

Haptoglobin phenotype was determined as described by Hochberg et al. [43]. Briefly, serum $(10 \mu \mathrm{L})$ was mixed with $2 \mu \mathrm{L}$ of a $10 \%$ hemoglobin solution, and the samples were incubated for $5 \mathrm{~min}$ at room temperature to permit the haptoglobin-hemoglobin complexes to form. The haptoglobin-hemoglobin complex was resolved by polyacrylamide electrophoresis. The haptoglobin-hemoglobin complexes were visualized by soaking the gel in freshly prepared staining solution. The bands corresponding to the haptoglobin-hemoglobin complex were readily visible within $15 \mathrm{~min}$. All gels were documented with photographs. Phenotypes $\mathrm{Hp} \mathrm{1-1,} \mathrm{Hp} \mathrm{2-2,} \mathrm{and} \mathrm{Hp} \mathrm{2-1} \mathrm{were}$ distinguished by a characteristic pattern of bands representing the haptoglobin-hemoglobin complexes.

\section{Statistical analysis}

Data are expressed as means \pm SEM. Microsoft Excel software was used to analyze data, create standard curves and draw figures. Statistical significance was assessed by one-way analysis of variance (ANOVA) for repeated measures. Tukey's multiple comparisons test was used for data point comparisons in each group. $\mathrm{P} \leq$ 0.05 was considered statistically significant.

\section{Results and discussion}

The average age of the studied 26 patients was $63.8 \pm$ 2.84 years (Table 1 ). Thirteen of them were males and the rest females. Administration of IVIR for 4 weeks did not increase hemoglobin levels $(10.23 \pm 0.28$ vs. $10.31 \pm 0.28 \mathrm{~g} \% \mathrm{p}=\mathrm{NS}$ ) (Table 2), yet worsened the oxidative burden as was evident by elevated plasma AOPP from basal value of $229.1 \pm 27.32$ to $318.1 \pm 39.63 \mu \mathrm{M}$ $(\mathrm{p}<0.05)$, and $367.8 \pm 41.8(\mathrm{p}<0.05)$ after 1 and 4 weeks, respectively (Fig. 2). Plasma NGAL levels were not significantly affected by IVIR $(265.4 \pm 48.55$ vs. $265.1 \pm 44.7$ and $205.7 \pm 39.41 \mathrm{ng} / \mathrm{ml}$, after 1 and 4 weeks, respectively) (Fig. 3). Simultaneous administration of carnitine with IVIR resulted in a mild hemoglobin increase (11.18 \pm $0.26 \mathrm{~g} \%, \mathrm{p}=\mathrm{NS}$ ) (Table 2). Interestingly, carnitine therapy abolished the IVIR-induced oxidative stress as evident by preventing the elevations in AOPP $(228.7 \pm 31.85$ vs. $237.4 \pm 31.85$ and $271.8 \pm 23.8 \mu \mathrm{M}$ after 1 and 4 weeks, respectively, $\mathrm{p}=\mathrm{NS}$ ) (Fig. 2). Furthermore, carnitine therapy decreased NGAL levels from $281.8 \pm 49.41$ to $201.3 \pm$ $36.63(\mathrm{p}<0.05)$, and $239 \pm 48.55 \mathrm{ng} / \mathrm{ml}(\mathrm{p}<0.05)$ after 1 and 4 weeks, respectively (Fig. 3). No changes in CRP, Serum Cr, BUN, albumin or WBC were observed following IVIR alone or combined with carnitine (Table 2). These findings indicate that IVIR in CKD patients provokes oxidative stress, as evident by elevation of circulating AOPP. Our finding, that co-administration of carnitine with IVIR attenuates the adverse consequences of IVIR, suggests a role for carnitine therapy also in earlier-stage CKD patients.

\section{Haptoglobin phenotype}

This protocol was designed in order to examine whether Hp phenotype affects iron-induced oxidative stress in CKD patients. Figure 4 depicts the distribution of $\mathrm{Hp}$ gene polymorphism among the studied CKD patients. Eight percent of the CKD patients were Hp 1-1, $19 \%$

Table 2 Effect of Carnitine therapy on biochemical and hematological characteristics of patients with CKD treated with intravenous administration of iron

\begin{tabular}{lcccccc}
\hline Parameter & Pre IVIR-W1 & Post IVIR-W1 & Post IVIR-W4 & Pre IVIR+CAR-W5 & Post IVIR+CAR-W5 & Post IVIR+CAR-W8 \\
\hline Creatinine (mg \%) & $2.5 \pm 0.31$ & $2.48 \pm 0.36$ & $2.38 \pm 0.32$ & $2.43 \pm 0.31$ & $2.27 \pm 0.35$ & $2.59 \pm 0.44$ \\
Albumin (g \%) & $4.05 \pm 0.08$ & $3.88 \pm 0.09$ & $3.83 \pm 0.07$ & $4.08 \pm 0.07$ & $3.92 \pm 0.06$ & $3.98 \pm 0.1$ \\
BUN (mg \%) & $42.4 \pm 5.4$ & $42.5 \pm 6.3$ & $37.3 \pm 4.5$ & $43.6 \pm 5.7$ & $38.6 \pm 5.6$ & $45.3 \pm 8.1$ \\
CRP & $0.74 \pm 0.19$ & $0.61 \pm 0.13$ & $0.54 \pm 0.11$ & $0.66 \pm 0.11$ & $0.53 \pm 0.09$ & $0.94 \pm 0.32$ \\
WBC & $6.67 \pm 0.49$ & $6.65 \pm 0.49$ & $5.92 \pm 0.43$ & $6.65 \pm 0.55$ & $6.25 \pm 0.54$ & $6.64 \pm 0.58$ \\
NEU \% & $66.7 \pm 1.65$ & $67.3 \pm 1.66$ & $66.5 \pm 1.67$ & $68.9 \pm 1.46$ & $66.3 \pm 1.85$ & $64.95 \pm 1.86$ \\
LYM \% & $22.3 \pm 1.3$ & $22.3 \pm 1.5$ & $23.2 \pm 1.56$ & $20.4 \pm 1.26$ & $23.3 \pm 1.51$ & $23.65 \pm 1.6$ \\
Hb (g \%) & $10.3 \pm 0.25$ & $10.0 \pm 0.33$ & $10.5 \pm 0.21$ & $10.8 \pm 0.19$ & $10.4 \pm 0.17$ & $11.02 \pm 0.22$ \\
\hline
\end{tabular}




\section{AOPP LEVELS}

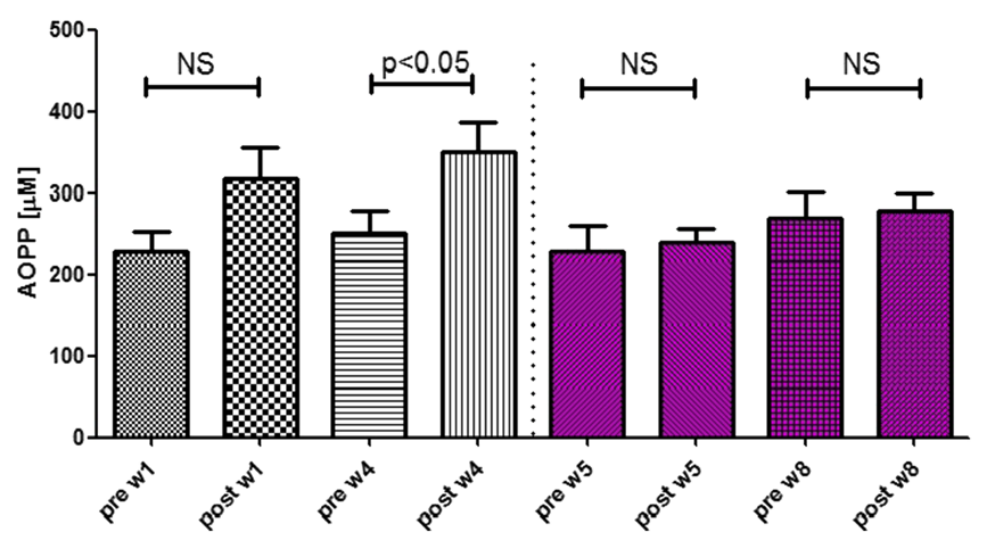

Fig. 2 Effects of Carnitine therapy on AOPP levels in patients with CKD treated with intravenous administration of iron. AOPP levels were determined in blood samples drawn 1 and 8 weeks prior and post iron administration (Sodium ferric gluconate, 125 mg/100 ml) During weeks $5-8$, these patients received carnitine $(20 \mathrm{mg} / \mathrm{kg}$, IV) prior to IVIR

Hp 2-1, and $73 \% \mathrm{Hp} \mathrm{2-2.} \mathrm{The} \mathrm{alterations} \mathrm{in} \mathrm{plasma}$ AOPP and NGAL in response to IVIR in the absence or presence of carnitine therapy in these patients according to their Hp phenotype are depicted in Fig. 5. As can be noticed, the increase in AOPP after 4 weeks from IVIR administration was more prominent in $\mathrm{Hp} 2-2$ patients (Fig. 5a). Carnitine therapy reduced plasma levels of NGAL in Hp 2-2 patients administered with IVIR more profoundly than that observed in Hp2-1 subjects (Fig. 5b).

The present study provides new insights into the mechanisms underlying the oxidative stress response to intravenous administration of iron (IVIR) to predialytic CKD patients. We showed that IVIR to these patients provoked oxidative stress as was evident by elevated levels of AOPP. Carnitine therapy significantly reduced the oxidative stress response to IVIR as expressed by lower levels of AOPP. Although, IVIR did not increase circulatory levels of NGAL, administration of carnitine decreased plasma levels of NGAL below basal concentrations. Noteworthy, overwhelming majority of CKD patients are of Hp 2-2 phenotype. The latter were more sensitive to the oxidative stress response to IVIR than

\section{NGAL LEVELS}

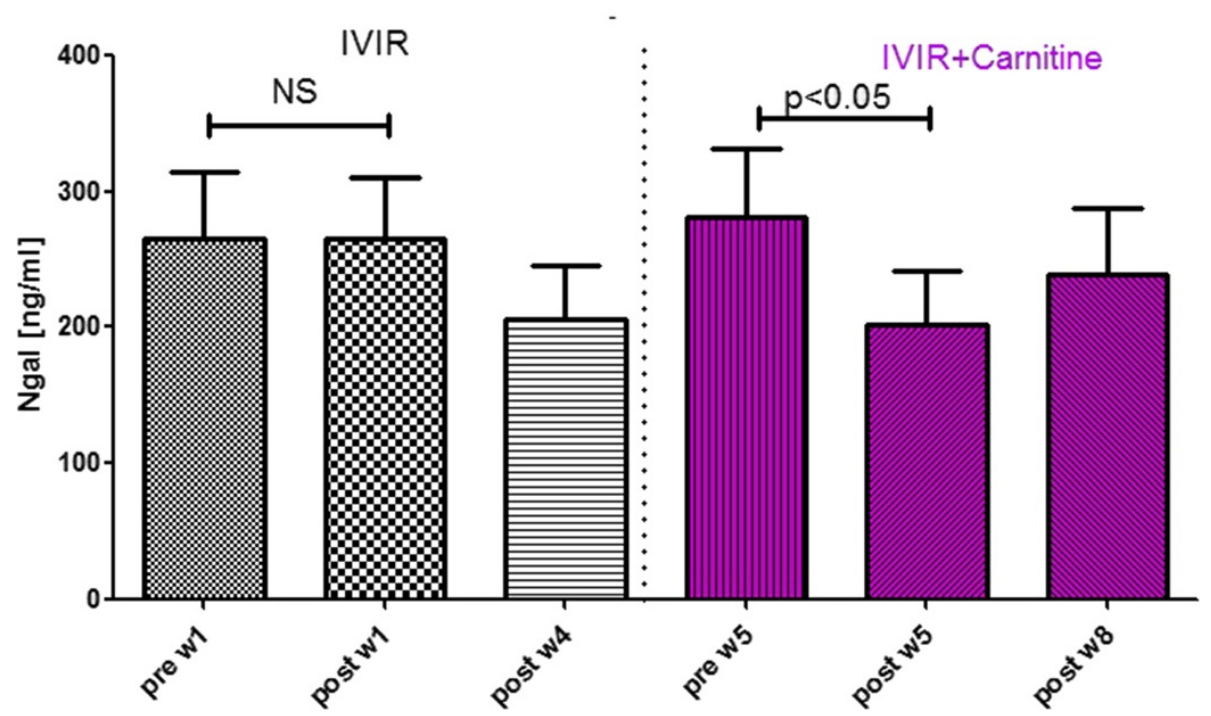

Fig. 3 Effects of Carnitine therapy on plasma NGAL levels in patients with CKD treated with intravenous administration of iron. NGAL levels were determined in blood samples drawn 1 and 8 weeks prior and post iron administration (Sodium ferric gluconate, $125 \mathrm{mg} / 100 \mathrm{ml}$ ) During weeks $5-8$, these patients received carnitine $(20 \mathrm{mg} / \mathrm{kg}$, IV) prior to IVIR 


\section{Haptoglobin Genotype in CKD patients}

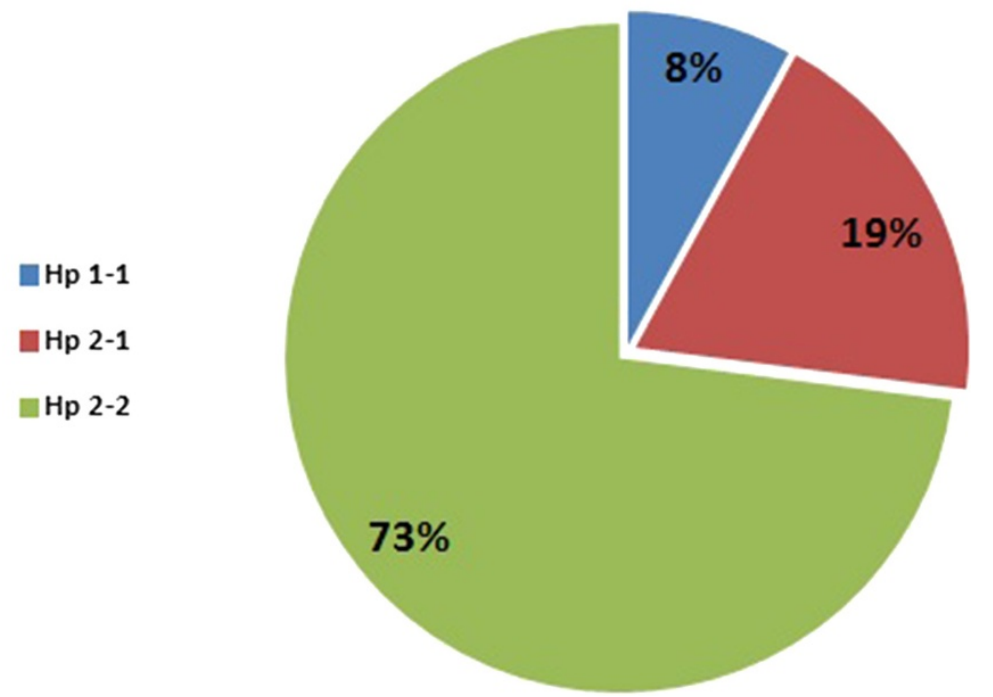

Fig. 4 Distribution of haptoglobin phenotype among the studied CKD patients

others, suggesting that $\mathrm{Hp}$ gene polymorphism plays a role in the pathogenesis of IVIR-induced oxidative stress. Unfortunately, IVIR administration for 8 weeks did not increase $\mathrm{Hb}$ levels in CKD patients. However, simultaneous administration of Carnitine with IVIR resulted in a mild elevation of hemoglobin concentrations. No changes in CRP, Serum Cr, BUN, albumin or WBC were observed following IVIR alone or combined with Carnitine.

Oxidative stress is a constant feature of patients with CKD and a major risk factor for cardiovascular, neurological and other clinical complications characterizing this disease [4-6]. Intravenous administration of iron in conjunction with EPO is frequently utilized in order to correct the anemia associated with CKD $[7,9,10]$. Although iron administration composes an essential component of CKD therapy, concerns have emerged about its promotion of oxidative stress and related adverse impact. The deleterious pro oxidative effects were extensively studied mainly in dialytic patients $[10,16]$ and to a lesser extent in pre dialytic subjects [11]. Whether patients with CKD not on dialysis have a similar increase in oxidative stress and, above all, renal injury upon exposure to intravenous iron is unknown. This issue is of critical importance since oxidative stress and renal injury may accelerate renal deterioration and increase the risk of cardiovascular disease [4-6, 44]. Thus, the current study addresses this matter and extends our knowledge in that respect. Our findings clearly show that IVIR administration for few weeks induced oxidative stress also in pre dialytic CKD patients. This was evident by a significant elevation of AOPP, a marker of plasma proteins oxidation. These findings are in agreement with those of
Anraku et al. [44] who demonstrated elevated levels of AOPP following IVIR for 4 weeks to dialytic patients. Drüeke et al. [45] demonstrated that advanced oxidation protein products (AOPPs) correlated with iron exposure and carotids artery intima thickness in dialysis patients. In hemodialysis patients, oxidative stress as a result of intravenous iron therapy caused serum albumin oxidation [46]. Similar to our findings, Agarwal et al. [11] demonstrated that $100 \mathrm{mg}$ iron sucrose over $5 \mathrm{~min}$ to patients with CKD at stages 3 and 4 increased plasma concentration and urinary excretion rate of MDA, a biomarker of lipid peroxidation, within 15 to $30 \mathrm{~min}$ of iron sucrose administration. In contrast to the stimulatory effect of IVIR on AOPP, our findings show that NGAL did not increase following iron administration. NGAL is upregulated and overexpressed following AKI, and its plasma and urinary levels increased early after renal ischemia in mouse and rat models [34], and following renal ischemic insult in human undergoing pulmonary bypass surgery [32]. The lack of stimulatory effects of IVIR on plasma NGAL in our patients indicates that iron administration did not cause serious AKI [47]. It should be emphasized that plasma NGAL also increases during inflammatory diseases and infections [32], suggesting that the decline in plasma NGAL when carnitine was added could be attributed to the anti-inflammatory effect of carnitine.

So far there is no effective pharmacological therapy for oxidative stress-induced by iron administration. Neither vitamin $\mathrm{C}$ nor vitamin $\mathrm{E}$ supplementation was found to ameliorate oxidative stress and inflammation in ESRD patients [48]. Likewise, NAC reduced acute generation 


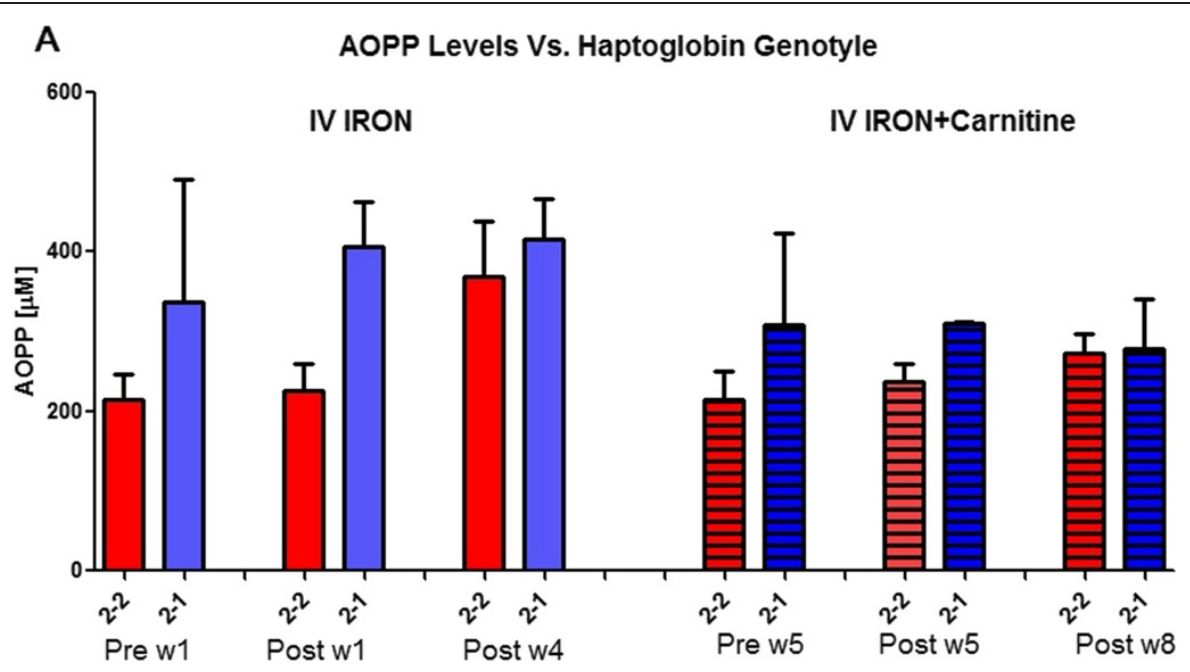

B

NGAL Levels Vs. Haptoglobin Genotyle

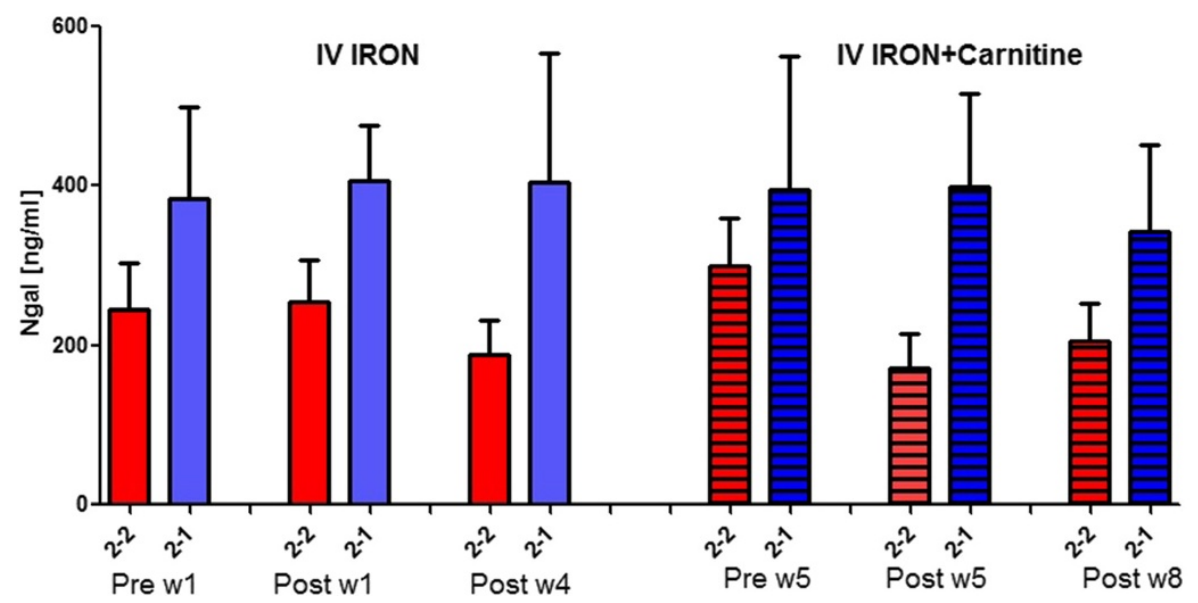

Fig. 5 Effect of Haptoglobin phenotype on a) AOPP and b) NGAL levels in patients with CKD treated with intravenous administration of iron. AOPP and NGAL levels were determined in blood samples drawn 1 and 8 weeks prior and post iron administration (Sodium ferric gluconate, $125 \mathrm{mg} / 100 \mathrm{ml})$. During weeks 5-8, these patients received Carnitine (20 mg/kg, IV) prior to IVIR administration

of systemic oxidative stress but failed to abrogate proteinuria or enzymuria induced by $100 \mathrm{mg}$ iron sucrose to CKD patients [11]. In this context, animal and human data demonstrate beneficial effects of carnitine in experimental models and clinical settings of oxidative stress including hemodialysis [49].

Experimental studies shows beneficial effects of Lpropionylcarnitine, a propionyl ester of L-carnitine, in preventing cyclosporine-induced acute nephrotoxicity, reducing lipid peroxidation and significantly lowering blood pressure. L-propionyl carnitine prevented the decline in creatinine clearance (GFR) in cyclosporine chronically treated animals [50]. Clinical studies revealed that ESRD patients treated with carnitine displayed improved physical performance and treatment-related chronic fatigue, cardiovascular disease, cancer, diabetes, and other chronic syndromes, related to impaired carnitine production in kidney disease [49]. In the last decade there are increasing reports describing the beneficial use of carnitine for a better energy metabolism (mitochondrial metabolism). In this context Carnitine increases albumin and protein levels, restores antioxidant defenses, and improves nutritional status, cardiac, vascular smooth muscle, and muscular function [51]. The postulated beneficial effect of carnitine treatment is due to directing lipids towards oxidation and ATP production. Another possible protective effect of carnitine on CKD is its ability to suppress the development of oxidative stress and free radical generation [52]. In line with this notion, our results clearly indicate anti-oxidative properties of carnitine as was evident by reducing AOPP and NGAL levels in CKD patients treated with IVIR.

Finally, our study is the first to our knowledge to investigate the impact of $\mathrm{Hp}$ gene polymorphism on the oxidative response to IVIR to CKD patients. Interestingly, most 
of the studied patients were Hp 2-2 (73\%) whereas only $8 \%$ were $\mathrm{Hp} \mathrm{1-1.} \mathrm{Similarly,} \mathrm{the} \mathrm{frequency} \mathrm{of} \mathrm{Hp2-2} \mathrm{geno-}$ type allele was significantly higher in the CKD Taiwanese patients than in controls [53]. After adjustment for covariates, the Hp2-2 genotype (vs. Hp1-1; OR 3.841) remained significantly associated with the development of CKD, together with diabetes (OR 3.131), hypertension (OR 1.748) and dyslipidemia (OR 1.646). Taking into account that Hp plays a role in renal protection, these findings suggest Hp2-2 genotype is an independent risk factor for CKD. Our data support this concept and show that CKD patients of $\mathrm{Hp} 2-2$ allele are more prone to develop oxidative stress in response to IVIR than other Hp alleles. Additional larger and longer clinical trials are requested to verify this concept.

\section{Conclusions}

This study demonstrates that intravenous administration of iron to CKD patients provokes oxidative stress as expressed by elevated AOPP levels. Administration of Carnitine to CKD patients reduces the oxidative burden induced by IVIR. The anti-oxidative effects of Carnitine, suggests a role for Carnitine therapy also in earlier-stage CKD patients. Since Hp 2-2 is a significant risk factor for IVIR-induced oxidative stress in CKD patients, the latter may benefit from carnitine therapy more than other Hp genotypes.

\section{Abbreviations \\ AOPP: Advanced oxidative protein products; CKD: Chronic kidney disease; CRP: C-reactive protein; Epo: Erythropoietin; HD: Hemodialysis; Hp: Haptoglobin; MDA: Malondialdehyde; IVIR: Intravenous iron administration; NGAL: Neutrophil gelatinase-associated lipocalin.}

\section{Competing interests}

The authors declare that they have no competing interests.

\section{Authors' contributions}

ZA: Design of the work, mobilizing the patients, interpretation of data, writing the MS. A E-Q: Chemical analysis, collecting the data, preparing the figures and tables. AJ: Chemical analysis, collecting the data, collecting the data, writing the MS. KH: Design of the work, interpretation of data, drafting the work. RR: Design of the work, interpretation of data, drafting the work. $A B$ : Design of the study, revising the MS critically for important intellectual content. BB: Interpretation of data, revising the MS critically for important intellectual content. All authors read and approved the final manuscript.

\section{Acknowledgement}

This study was supported by Migal, Galilee Technology Institute, Israel.

\section{Author details}

'Department of Nephrology, Nazareth Hospital-EMMS, Nazareth 16100, Israel. 2Department of Laboratory Medicine, Nazareth Hospital-EMMS, Nazareth, Israel. ${ }^{3}$ Galilee Faculty of Medicine - Bar Ilan University, Zafed, Israel. ${ }^{4}$ Department of Nephrology, Western Galilee Hospital, Nahariya, Israel. ${ }^{5}$ Department of Nephrology, Rambam Health Campus, Haifa, Israel.

Received: 27 November 2014 Accepted: 20 July 2015

Published online: 13 August 2015

\section{References}

1. Levey AS, Andreoli SP, DuBose T, Provenzano R, Collins AJ. Chronic kidney disease: common, harmful, and treatable-World Kidney Day 2007. Clin J Am Soc Nephrol. 2007;2:401-5.

2. Coresh J, Selvin E, Stevens LA, Manzi J, Kusek JW, Eggers P, et al. Prevalence of chronic kidney disease in the United States. JAMA. 2007;298:2038-47.

3. Besarab A, Schrier RW, Gottschalk CW. Anemia in Renal Disease. Dis Kidney. 1997:3:2581-92

4. Sarnak MJ, Levey AS, Schoolwerth AC, Coresh J, Culleton B, Hamm LL, et al. Kidney disease as a risk factor for development of cardiovascular disease: a statement from the American Heart Association Councils on Kidney in Cardiovascular Disease, High Blood Pressure Research, Clinical Cardiology, and Epidemiology and Prevention. Circulation. 2003;108:2154-69.

5. Coresh J, Astor B, Sarnak MJ. Evidence for increased cardiovascular disease risk in patients with chronic kidney disease. Curr Opin Nephrol Hypertens. 2004;13:73-81.

6. Go AS, Chertow GM, Fan D, McCulloch CE, Hsu CY. Chronic kidney disease and the risks of death, cardiovascular events, and hospitalization. N Engl J Med. 2004;351:1296-305.

7. Fishbane S, Maesaka JK. Iron management in end-stage renal disease. Am J Kidney Dis. 1997;29:319-33.

8. Babitt JL, Lin HY. Mechanisms of anemia in CKD. J Am Soc Nephrol. 2012;23:1631-4.

9. Macdougall IC, Chandler G, Elston O, Harchowal J. Beneficial effects of adopting an aggressive intravenous iron policy in a hemodialysis unit. Am J Kidney Dis. 1999;34:S40-6.

10. Besarab A, Coyne DW. Iron supplementation to treat anemia in patients with chronic kidney disease. Nat Rev Nephrol. 2010;6:699-710.

11. Agarwal R, Vasavada N, Sachs NG, Chase S. Oxidativestress and renal injury with intravenous iron-in patients with chronic kidney disease. Kidney Int. 2004;65:2279-89.

12. Lim PS, Wei $Y H, Y u$ YL, Kho B. Enhanced oxidative stress in haemodialysis patients receiving intravenous iron therapy. Nephrol Dial Transplant. 1999;14:2680-7.

13. Roob JM, Khoschsorur G, Tiran A, Horina JH, Holzer H, Winklhofer-Roob BM. Vitamin $\mathrm{E}$ attenuates oxidative stress induced by intravenous iron in patients on hemodialysis. J Am Soc Nephrol. 2000;11:539-49.

14. Leehey DJ, Palubiak DJ, Chebrolu S, Agarwa R. Sodium ferric gluconate causes oxidative stress but not acute renal injury in patients with chronic kidney disease: a pilot study,". Nephrol Dial Transplant. 2005;20:135-40.

15. Koskenkorva-Frank TS, Weiss G, Koppenol WH, Burckhardt S. The complex interplay of iron metabolism, reactive oxygen species, and reactive nitrogen species: insights into the potential of various iron therapies to induce oxidative and nitrosative stress. Free Radic Biol Med. 2013;65:1174-94.

16. Stefánsson BV, Haraldsson B, Nilsson U. Acute oxidative stress following intravenous iron injection in patients on chronic hemodialysis: a comparison of iron-sucrose and iron-dextran. Nephron Clin Pract. 2011;118:c249-56.

17. Witko-Sarsat V, Gausson V, Nguyen AT, Touam M, Drüeke T, Santangelo F, et al. AOPP-induced activation of human neutrophil and monocyte oxidative metabolism: a potential target for $\mathrm{N}$-acetylcysteine treatment in dialysis patients. Kidney Int. 2003;64:82-91.

18. Witko-Sarsat V, Gausson V, Descamps-Latscha B. Are advanced oxidation protein products potential uremic toxins? Kidney Int Suppl. 2003;84:S11-4.

19. Witko-Sarsat V, Friedlander M, Capeillère-Blandin C, Nguyen-Khoa T, Nguyen AT, Zingraff J, et al. Advanced oxidation protein products as a novel marker of oxidative stress in uremia. Kidney Int. 1996;49:1304-13.

20. Odetti P, Garibaldi S, Gurreri G, Aragno I, Dapino D, Pronzato MA, et al. Protein oxidation in hemodialysis and kidney transplantation. Metabolism. 1996:45:1319-22.

21. Girotti AW. Lipid hydroperoxide generation, turnover, and effector action in biological systems. J Lipid Res. 1998;39:1529-42.

22. Montuschi P, Barnes PJ, Roberts II $\amalg$. Isoprostanes: markers and mediators of oxidative stress. FASEB J. 2004;18:1791-800.

23. Islam KN, O'Byrne D, Devaraj S, Palmer B, Grundy SM, Jialal I. Alphatocopherol supplementation decreases the oxidative susceptibility of LDL in renal failure patients on dialysis therapy. Atherosclerosis. 2000;150:217-24.

24. Levy AP, Hochberg I, Jablonski K, Resnick HE, Lee ET, Best L, et al. Strong Heart Study. Haptoglobin phenotype is an independent risk factor for cardiovascular disease in individuals with diabetes: The Strong Heart Study. J Am Coll Cardiol. 2002;40:1984-90.

25. Levy AP, Asleh R, Blum S, Levy NS, Miller-Lotan R, Kalet-Litman S, et al. Haptoglobin: basic and clinical aspects. Antioxid Redox Signal. 2010;12:293-304. 
26. Bowman BH, Kurosky A. Haptoglobin: the evolutionary product of duplication, unequal crossing over, and point mutation. Adv Hum Genet. 1982;12:189-261.

27. Bamm W, Tsemakhovich VA, Shaklai M, Shaklai N. Haptoglobin phenotypes differ in their ability to inhibit heme transfer from hemoglobin to LDL. Biochemistry. 2004:43:3899-906.

28. Asleh R, Blum S, Kalet-Litman S, Alshiek J, Miller-Lotan R, Asaf R, et al. Correction of HDL dysfunction in individuals with diabetes and the haptoglobin genotype. Diabetes. 2008;57:2794-800.

29. Schrier RW, Wang W, Poole B, Mitra A, et al. Acute renal failure: definitions, diagnosis, pathogenesis, and therapy. J Clin Invest. 2004;114:5-14.

30. Lameire N, Van Biesen W, Vanholder R. Acute renal failure. Lancet. 2005;365:417-30.

31. Moran SM, Myers BD. Course of acute renal failure studied by a model of creatinine kinetics. Kidney Int. 1985;27:928-37.

32. Devarajan P. Neutrophil gelatinase -associated lipocalin: A troponin-like biomarker for human acute kidney injury. Nephrol. 2010;15:419-28.

33. Vaidya VS, Ferguson MA, Bonventre JV. Biomarkers of acute kidney injury. Annu Rev Pharmacol Toxicol. 2008:48:463-93.

34. Mishra J, Ma Q, Prada A, Mitsnefes M, Zahedi K, Yang J, et al. Identification of neutrophil gelatinase-associated lipocalin as a novel early urinary biomarker for ischemic renal injury. J Am Soc Nephrol. 2003;14:2534-43.

35. Mishra J, Dent C, Tarabishi R, Mitsnefes MM, Ma Q, Kelly C, et al. Neutrophil gelatinase-associated lipocalin (NGAL) as a biomarker for acute renal injury after cardiac surgery. Lancet. 2005;365:1231-8.

36. Ichimura T, Bonventre JV, Bailly V, Wei H, Hession CA, Cate RL, et al. Kidney injury molecule-1 (KIM-1), a putative epithelial cell adhesion molecule containing a novel immunoglobulin domain, is up-regulated in renal cells after injury. J Biol Chem. 1998;273:4135-42.

37. Ichimura T, Asseldonk EJ, Humphreys BD, Gunaratnam L, Duffield JS, Bonventre $\mathrm{JV}$, et al. Kidney injury molecule-1 is a phosphatidylserine receptor that confers a phagocytic phenotype on epithelial cells. J Clin Invest. 2008;118:1657-68.

38. Labonia WD. L-carnitine effects on anemia in hemodialyzed patients treated with erythropoietin. Am J Kidney Dis. 1995;26:757-64.

39. Caruso U, Leone L, Cravotto E, Nava D. Effects of L-carnitine on anemia in aged hemodialysis patients treated with recombinant human erythropoietin: a pilot study. Dial Transplant. 1998;27:499-506

40. Kletzmayr J, Mayer G, Legenstein E, Heinz-Peer G, Leitha T, Hörl WH, et al. Anemia and carnitine supplementation in hemodialyzed patients. Kidney Int Suppl. 1999;69:S93-106.

41. Steiber AL, Davis AT, Spry L, Strong J, Buss ML, Ratkiewicz MM, et al. Carnitine treatment improved quality-of-life measure in a sample of Midwestern hemodialysis patients. JPEN J Parenter Enteral Nutr. 2006;30:10-5.

42. Yee J. L-Carnitine for Anemia in Hemodialysis Patients: A Last Resort. Clin J Am Soc Nephrol. 2012;7:1746-8.

43. Hochberg I, Roguin A, Nikolsky E, Chanderashekhar PV, Cohen S, Levy AP. Haptoglobin phenotype and coronary artery collaterals in diabetic patients. Atherosclerosis. 2002;161:441-6.

44. Anraku M, Kitamura K, Shintomo R, Takeuchi K, Ikeda H, Nagano J, et al. Effect of intravenous iron administration frequency on AOPP and inflammatory biomarkers in chronic hemodialysis patients: a pilot study. Clin Biochem. 2008;41:1168-74.

45. Drüeke T, Witko-Sarsat V, Massy Z, Descamps-Latscha B, Guerin AP, Marchais SJ, et al. Iron therapy, advanced oxidation protein products, and carotid artery intima-media thickness in end-stage renal disease. Circulation. 2002;106:2212-7.

46. Anraku M, Kitamura K, Shinohara A, Adachi M, Suenga A, Maruyama T, et al. Intravenous iron administration induces oxidation of serum albumin in hemodialysis patients. Kidney Int. 2004;66:841-8.

47. Haugen E, Nath KA. The involvement of oxidative stress in the progression of renal injury. Blood Purif. 1999;17:58-65.

48. Kamgar M, Zaldivar F, Vaziri ND, Pahl MV. Antioxidant therapy does not ameliorate oxidative stress and inflammation in patients with end-stage renal disease. J Natl Med Assoc. 2009;101:336-44.

49. Bellinghieri G, Santoro D, Calvani M, Mallamace A, Savica V. Carnitine and hemodialysis. Am J Kidney Dis. 2003:41(3 Suppl 1):S116-22.

50. Bertelli A, Giovannini L, Palla R, Migliori M, Panichi V, Andreini B. Protective effect of L-propionylcarnitine on cyclosporine-induced nephrotoxicity. Drugs Exp Clin Res. 1995;21:221-8.
51. Di Lisa F, Barbato L, Menabo R, Siliprandi N. Carnitine and mitochondrial dysfunction. In: De Simone C, Famularo G, editors. Carnitine Today. London: Chapman \& Hall Publishers; 1997. p. 95-104.

52. Dokmeci D, Akpolat M, Aydogu N, Uzal C, Doganay L, Turan FN. The protective effect of $L$-carnitine on ionizing radiation induced free oxygen radicals. Scand J Lab Anim Sci. 2006;33:75-83.

53. Chen YC, Lee CC, Huang CY, Huang HB, Yu CC, Ho YC, et al. Haptoglobin polymorphism as a risk factor for chronic kidney disease: a case-control study. Am J Nephrol. 2011;33:510-4.

\section{Submit your next manuscript to BioMed Central and take full advantage of:}

- Convenient online submission

- Thorough peer review

- No space constraints or color figure charges

- Immediate publication on acceptance

- Inclusion in PubMed, CAS, Scopus and Google Scholar

- Research which is freely available for redistribution

Submit your manuscript at www.biomedcentral.com/submit 